\title{
Perspectivas da população brasileira sobre as vacinas COVID-19 como método de prevenção
}

\section{Perspectives of the brazilian population on the use of vaccines against COVID-19 in prevetion method}

\author{
Marcos Mourão Santa Brígida ${ }^{11^{*}}$, Rafaela Assumpção ${ }^{2}$, Yara Marina Reymao de Barros ${ }^{1}$, Jeany \\ Costa da Silva ${ }^{1}$, Raquel Soares Casaes Nunes ${ }^{1}$
}

\begin{abstract}
RESUMO
O Programa Nacional de Imunização proporciona a cobertura vacinal dos imunobiológicos do Sistema único de Saúde para a população. Entre as diversas tecnologias de produção das vacinas que estão sendo avaliadas, inclui-se as que estão sendo realizadas com os ácidos nucleicos; uso de vetores virais; vacinas virais inativadas e as vacinas proteicas recombinantes - partículas semelhantes ao virus. Na pandemia atual do País, as vacinas que estão prontas para utilização são das empresas Astrazeneca, Sinovac e Pfizer. O Objetivo do trabalho foi avaliar o conhecimento da população quanto à eficácia e a importância da vacinação como método preventivo à doença COVID 19 para a população brasileira. Foi realizado um questionário com 6 perguntas e um total de 38 participantes foram entrevistados, mencionando entre as suas respostas que um quantitativo de $80 \%$ dos entrevistados não apresentam dúvidas sobre os imunizantes da COVID, entretanto $77 \%$ destes mencionam a necessidade de divulgação científica em mídias sociais sobre a importância da vacinação. Contudo, existe uma falta de conhecimento da população sobre as vacinas, com relação a confiabilidade da erradicação e/ou redução da doença com a vacinação em massa.
\end{abstract}

Pal avras chave: Imunização; Coronavac; Vacina de Oxford; Pfizer; SUS.

No mesmo idioma do artigo, com no mínimo cinco e no máximo 12 linhas. Deve constar em fonte Times New Roman, corpo 10, justificado, espaçamento 1,15 entre as linhas. O resumo é obrigatório e considerado um dos principais componentes do manuscrito. Lembre-se que um bom resumo deve descrever quais são os objetivos do trabalho e os pontos metodológicos de forma sucinta. Mostrar os principais resultados que respondem ao propósito do estudo.

Palavras-chave: Palavra-chave 1; Palavra-chave 2; Palavra-chave 3;

\section{ABSTRACT}

The National Immunization Program provides vaccine coverage of immunobiologicals from the Unified Health System for the population. Among the various vaccine production technologies that are being evaluated are those being carried out with nucleic acids; use of viral vectors; inactivated viral vaccines and recombinant protein vaccines - virus-like particles. In the country's current pandemic, the vaccines that are

\footnotetext{
${ }^{1}$ Universidade Federal Rural da Amazônia (UFRA) Belém-PA, Brasil *Email: marcosmourao@furg.br

2 Universidade Federal do Amazonas (UFAM) , Manaus - AM, Brasil
} 
ready for use are from the companies Astrazeneca, Sinovac and Pfizer. The objective of the study was to evaluate the population's knowledge about the efficacy and importance of vaccination as a preventive method for the disease COVID 19 for the Brazilian population. A questionnaire was conducted with 6 questions and a total of 38 participants were interviewed, mentioning among their answers that $80 \%$ of respondents have no doubts about COVID's immunization agents, however $77 \%$ of these mention the need for scientific dissemination on social media about the importance of vaccination. However, there is a lack of knowledge of the population about vaccines, regading the reliability of eradication and/or disease reduction with mass vaccination.

Keywords: Immunization; Coronavac; Oxford vaccine; Pfizer; SUS.

\section{INTRODUÇÃO}

O Programa Nacional de Imunizações (PNI) conta com a credibilidade da população e da comunidade científica, e as coberturas vacinais têm sido superiores a 90\% para quase todos os imunobiológicos distribuídos pelo Sistema Único de Saúde (SUS). As vacinas estudadas para a COVID-19 visa induzir anticorpos neutralizantes contra as subunidades virais, a maior parte delas tendo como alvo a região RBD (do inglês domínio de ligação do receptor) da proteína a Spike (S) do coronavírus (MINISTÉRIO DA SAÚDE, 2021). Entre as diversas tecnologias de produção das vacinas que estão sendo avaliadas, inclui as seguintes plataformas tecnológicas, as vacinas que são realizadas com os ácidos nucleicos (DNA e RNA), uso de vetores virais (replicantes e não replicantes), vacinas virais (atenuadas ou inativadas) e as vacinas proteicas (recombinantes - partículas semelhantes ao vírus) (MUKHERJEE, 2020). No quadro 1, foram mencionadas as vacinas que estão sendo aplicadas na população brasileira.

Quadro 1 - Vacinas utilizadas no programa de vacinação do Brasil (Programa Nacional de Imunizações (PNI) pelo SUS) no combate ao novo coronavírus.

\begin{tabular}{l|l|l|l}
\hline Vacinas & $\begin{array}{l}\text { Laboratórios } \\
\text { responsáveis }\end{array}$ & $\begin{array}{l}\text { Eficácia } \\
\text { aproximada }\end{array}$ & $\begin{array}{l}\text { Quantidade } \\
\text { de doses }\end{array}$ \\
\hline Coronavac & Sinovac & $50,39 \%$ & 2 \\
\hline $\begin{array}{l}\text { Vacina de } \\
\text { Oxford }\end{array}$ & Astrazeneca & $70,42 \%$ & 2 \\
\hline Pfizer & Biontech & $91,3 \%$ & 2 \\
\hline
\end{tabular}

Fonte: O autor, 2021. 
Entre as diversas tecnologias na produção da vacina, O laboratório americano Moderna, em parceira com o Instituto Nacional de Saúde Americano (NIH), e, a vacina produzida pelo laboratório americano Pfizer, em parceria com a empresa de biotecnologia alemã BioNTech, apresentam as vacinas de RNA mensageiro que têm demonstrado, respostas imunes celular e humoral eficazes. O RNA vacinal é envolto em uma camada lipídica, evitando assim, sua degradação (KRAMMER, 2020) Por outro lado, a vacina do laboratório chinês Sinovac, utiliza o conteúdo viral (partícula viral) inativado, com cultivo celular do vírus em células Vero e posterior inativação. No Brasil, o laboratório, estabeleceu parceria com o governo do Estado de São Paulo, através do Instituto Butantan. Existe também as vacinas com vetores virais, como os Adenovírus que não são replicantes e têm da vasido os principais vetores virais utilizados nas plataformas de desenvolvimento para as vacinas COVID. Podem ser humanos (Ad5 e Ad26) ou de símios (Chipanzés ChAd) (MUKHERJEE, 2020).

Segundo Krammer (2020) a vacina ChAdOx1 nCoV-19, baseada em vetores virais, desenvolvida na Universidade de Oxford, na Inglaterra, em parceria com o laboratório AstraZeneca, induz robusta resposta imune, incluindo resposta celular, após a aplicação de duas doses, mostraram resposta específica de células $\mathrm{T}$ no $14^{\circ}$ dia após aplicação, com anticorpos neutralizantes detectados entre, apresentando perfil de segurança aceitável. A agência regulatória americana, Food and Drug Administration (FDA), informou que, para aprovação de uma vacina, deve haver comprovação de redução da ocorrência e gravidade da doença em pelo menos $50 \%$ dos pacientes (FDA, 2020). Estudos indicam que as empresas Pfizer e Moderna, a eficácia das suas vacinas apresenaram resultados acima de 90\%, sem efeitos adversos graves, demonstrando também a segurança destes imunobiológicos.

Os resultados da análise de eficácia primária provisória da AstraZeneca apontam para eficácia de 70\% e a SINOVAC (50,38\%) (FDA, 2020). Por outro lado, o Ministério da Saúde (2021) ressalta que os grupos antivacinismo que se proliferam em todo o mundo parecem ser pouco numerosos em nosso meio, mas podem colocar em risco o sucesso já obtido pelo PNI, com o controle das doenças infecciosas e a melhoria das condições de vida da população, principalmente no atual cenário de conflitos políticos e disseminação em massa de "fake News" a respeito das vacinas do Covid-19. 
O Objetivo do trabalho foi avaliar o conhecimento da população sobre as vacinas COVID 19 que estão sendo aplicadas na população brasileira, quanto à eficácia e a sua importância como método preventivo.

\section{MATERIAL E MÉTODOS}

Foi realizado um questionário com 38 entrevistados sobre o tema da Vacinação como método preventivo e apresentado um texto inicial contendo informações sobre as vacinas que estão sendo utilizadas aqui no país, conforme o quadro 2. Após, os entrevistados responderam as perguntas do Quadro 2.

Quadro 2 - Pesquisa realizada com 38 respondentes sobre a vacinação no território nacional.

\begin{tabular}{|l|}
\hline Perguntas: \\
\hline Seu nome \\
\hline Você tem alguma pessoa do grupo de risco que reside na sua casa? \\
\hline O que você conhece sobre as vacinas contra o Covid-19? \\
\hline $\begin{array}{l}\text { O imunizante precisa ser aplicado em } 80 \% \text { da população para diminuirmos a transmissão do vírus e } \\
\text { proteger as pessoas que não podem recebe-la. Após a leitura do texto você receberia a vacina? }\end{array}$ \\
\hline Para você as doses da vacina vão oferecer proteção? \\
\hline $\begin{array}{l}\text { Todas as vacinas passaram por } 3 \text { fases de testagem para confirmar sua eficácia. O que lhe mostra } \\
\text { dúvidas na sua utilização? }\end{array}$ \\
\hline $\begin{array}{l}\text { O que você indicaria aos órgãos de fiscalização e produção da vacina para solucionar os problemas de } \\
\text { falta de informação sobre a vacina? }\end{array}$ \\
\hline
\end{tabular}

Fonte: O autor, 2021.

\section{RESULTADOS E DISCUSSÃO}

Com base nas respostas dos 38 entrevistados, foram elaborados os resultados abaixo: Quando foi realizada a pergunta sobre a presença de algum morador na sua residência que pertencia ao grupo de risco da COVID-19, o Quantitativo de 38 entrevistados afirmaram que " sim" 11 informaram que "não "' apresentam familiares do grupo de risco, conforme o Gráfico 1. Segundo o PN I, são características de comorbidades, tais como: doença renal crônica, doenças cardiovasculares e cerebrovasculares, diabetes mellitus, hipertensão arterial grave, pneumopatias crônicas 
graves, anemia falciforme, câncer, obesidade mórbida ( $\mathrm{IMC} \geq 40$ ); síndrome de down; além de idade superior a 60 anos e indivíduos imunossuprimidos (Folegatti et al, 2020). Gráfico 1. Quantitativo de entrevistados que mencionaram a presença ou ausência de familiares do grupo de risco COVID 19 na sua residência.

Gráfico 1 - Quantitativo de entrevistados que mencionaram a presença ou ausência de familiares do grupo de risco COVID 19 na sua residência.

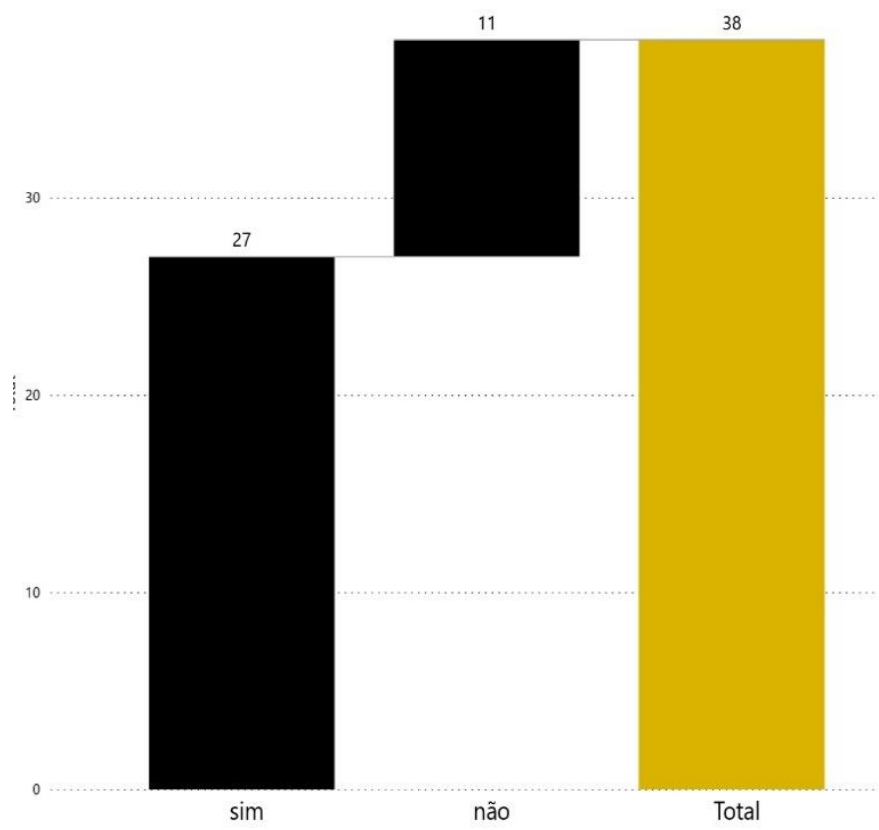

Fonte: O autor, 2021.

Ao Analisar a pergunta: O que você conhece sobre as vacinas contra o Covid19?, as respostas mais relevantes seguem abaixo:

-As vacinas foram testadas, entre elas as que utilizam o vírus enfraquecido ou inativos para estimular anticorpos, outras que usam genética (RNA) faz com que o corpo produza cópias de propinas do vírus estimulando resposta do sistema imunológico. Passam por um processo de 3 fases, são aprovadas para uso aquelas que atingem uma porcentagem de segurança.

-É necessário um período de 90 dias para imunização e ela será distribuída teoricamente a partir dos grupos de maiores ao de menores necessidades.

-A eficácia das vacinas não chega em 100\%, mas que é de suma importância que todos tomem. 
-As vacinas tem uma grande porcentagem de eficácia, porém aqui no Brasil ainda tá escassez a matéria prima das vacinas. Desta forma, acaba-se que por atrasando a vacinação da população. Nada muito específico.

- Que tem sua eficácia de 67 a 85\% Sim São 5 disponíveis, o governo tá disponilizando a coronavac, elas deveriam estar sendo distribuídas em larga escala, mas o processo está demorando por razões políticas. Que tem uma eficácia suficiente para que a pessoa não apresente quadros graves! -Todas as vacinas já aprovadas por agências reguladoras, como a Anvisa, obedecem ao critério mínimo para propor a proteção. As respostas da questão 2 obtiveram bastante relevância quanto a um conhecimento significativo da população ao perguntar sobre a importância da vacinação em pelo menos $80 \%$ da população para diminuição da transmissibilidade do vírus com a finalidade de proteção da população, todos os entrevistados responderam que receberiam a vacina. Conforme a tabela abaixo (tabela 1), $77 \%$ dos entrevistados, $\mathrm{n}=32$, não apresentam dúvidas sobre as 3 fases de avaliação da eficácia da vacina.

Tabela 1 - Percepção dos entrevistados sobre as vacinas usadas no combate ao covid-19 no território nacional.

\begin{tabular}{l|l|lr}
\hline Respostas & Quantitativo N=38 & Percentual (\%) & 7 \\
\hline $\begin{array}{l}\text { Não tenho dúvidas nesse } \\
\text { aspecto }\end{array}$ & 30 & & 12 \\
\hline Necessidade de mais testes & 5 & 6 \\
\hline $\begin{array}{l}\text { Apenas possíveis reações e } \\
\text { sequelas }\end{array}$ & 2 & & \\
\hline $\begin{array}{l}\text { Ambição da China em } \\
\text { vender a vacina a todo } \\
\text { custo }\end{array}$ & 1 & 4 & \\
\hline
\end{tabular}

Fonte: $\mathrm{O}$ autor, 2021.

- As respostas da pergunta sobre se as doses da vacina irão oferecer proteção? Todos os entrevistados concordaram que sim.

Tabela 2 - Respostas dos 38 respondentes a pergunta: "O que você indicaria aos órgãos de fiscalização para melhorar as informações sobre as vacinas"?

\begin{tabular}{|c|c|c|}
\hline Perguntas & QuantitativoN=38 & Percentual (\%) \\
\hline $\begin{array}{l}\text { Esclarecimento em massa } \\
\text { por meio das mídias } \\
\text { sociais (principal canal de } \\
\text { troca de informações } \\
\text { utilizado). }\end{array}$ & 31 & $81,6 \%$ \\
\hline
\end{tabular}




\begin{tabular}{|c|c|c|}
\hline $\begin{array}{l}\text { Que haja uma melhor } \\
\text { distribuição aos estados de } \\
\text { uma forma igualitária de } \\
\text { acordo com os números de } \\
\text { habitantes. Tendo em vista, } \\
\text { que também tem que ter uma } \\
\text { fiscalização bastante rigorosa } \\
\text { na produção e distribuição } \\
\text { dessa vacina. Apenas mais } \\
\text { transparência e repassar as } \\
\text { informações a todos de forma } \\
\text { acessível. }\end{array}$ & 4 & $10,53 \%$ \\
\hline $\begin{array}{l}\text { Treinamento para melhor } \\
\text { auxiliar o entendimento dos } \\
\text { demais } \\
\text { membros da sua } \\
\text { comunidade. }\end{array}$ & 2 & $5.26 \%$ \\
\hline $\begin{array}{l}\text { A forma mais eficiente de } \\
\text { sanar dúvidas sobre as } \\
\text { vacinas é a partir de } \\
\text { propaganda explicando e } \\
\text { estimulando, do mesmo } \\
\text { modo que era feito anos atrás }\end{array}$ & 1 & $2.63 \%$ \\
\hline
\end{tabular}

Fonte: O autor, 2021.

Na pergunta: O que você indicaria aos órgãos de fiscalização para melhorar as informações sobre as vacinas? Conforme a tabela 2, os 31 dos participantes indicaram a necessidade do esclarecimento em massa por meio das mídias sociais sobre as informações das vacinas a serem aplicadas na população: prioridades, ordem de aplicação. Muitas pessoas desconhecem informações sobre a imunidade de rebanho (não foram citadas nas respostas), com a necessidade de vacinação com 2 doses da vacina $70 \%$ das pessoas para eliminação/redução da doença (MINISTÉRIO DA SAÚDE, 2021). Pensar que já estão imunizadas e sem risco individualmente. Informações como estas necessitam ser incessantemente mencionadas nas mídias sociais, conforme o Ministério da Saúde relata em seus documentos escritos. Caso não alcancem a imunidade de rebanho, possíveis lockdown e perda econômica serão consequencias adjacentes a população como método preventivo (BRIGIDA et al, 2020). Por desconhecerem essa informação podem pensar que já estão imunizadas e sem risco individualmente. Informações como estas necessitam ser melhoradas nas mídias sociais, conforme o (MINISTÉRIO DA SAÚDE, 2021).

\section{CONSIDERAÇÕES FINAIS}


Conforme foi avaliado o conhecimento da população sobre as vacinas, há necessidade de maiores esclarecimentos através das mídias sociais sobre a confiabilidade da vacinação em massa ( $70 \%$ da população) para que haja a redução da transmissão do vírus. Portanto, em um momento inicial em que não se atinge esse percentual da população vacinado, o objetivo principal da vacinação passa a ser focado na redução da mortalidade causada pela covid-19 e combater os impactos adjacentes frisado por (BRIGIDA et al, 2020.).

\section{REFERÊNCIAS}

ALMEIDA, L.C. M ; STUGINSKI, J.B.; CONTI, P.C.R. How psychosocial and economic impacts of COVID-19 pandemic can interfere on bruxism and temporomandibular disorders. Journal of Applied Oral Science. Bauru-SP. v.28, p 13. 2020.

BARREIRA G; GRANDIN F. Bairros mais caros do Rio lideram casos, mas especialistas temem 'explosão' de Covid-19 nas favelas. O Globo, Rio de Janeiro. 2020. BRÍGIDA, M. M. S. ; QUADROS, E. S.; CASAES, R. S.; NUNES, R. S. C. Socioeconomic impacts and environmental consequences in the fight against covid-19: a case study. Brazilian. Journal. of Develop., Curitiba, v.6, n.11,p.89390-89400, nov.2020.

BROOKS SK, et al. The psychological impact of quarantine and how to reduce it: rapid review of the evidence. The lancet jornal. v. 395, p 912-920. 2020.

CARVALHO, F.A. Pandemia e Meio Ambiente: Impactos momentâneos ou nova normalidade. UFJF notícias. Juiz de Fora/MG. DENIS, Freitas. Quarentena diminui poluição do ar ao redor do mundo. Super Interessante. 2020.

FERRARI A; CUNHA, A.M. A pandemia de Covid-19 e o isolamento social: saúde versus economia. Universidade Federal do Rio Grande do Sul. Departamento de Economia e Relações Internacionais da UFRGS. 2020.

FILHO, S. Aumento do lixo pode chegar a $25 \%$ durante a pandemia do coronavírus. Revista Meio Ambiente Industrial. A ABRELPE -Associação Brasileira de Empresas de Limpeza Pública e Resíduos Especiais. 2020. FINLAY, B.B; HANCOCK, R.E. Can innate immunity be enhanced to treat microbialinfections? Nature Reviews Microbiology. 2004. [S.I]. 497-504.

Folegatti PM, Ewer KJ, Aley PK, et al. Safetyandimmunogenicityofthe ChAdOx1 nCoV-19 vaccine against SARS-CoV-2: a preliminaryreportof a phase $1 / 2$, single-blind, randomised controlled trial. Lancet.2020;396(10249):467-78. 
FORSTER P. et al. Phylogenetic network analysis of SARS-CoV-2 genomes. Rev:

Proceedings of the National Academy of Sciences -PNAS. v.17, n.17. p. 9241-9243. [S.I]. 2020.

GRELLET, F. Witzel suspende transporte por ônibus e avião para o Rio. Uol, São Paulo. 2020.

GRUBER, A. A origem do Sars-CoV-2. 2020. Pfarma. 2020.

JUCÁ B. Com projeção de $\mathbf{4 6 0 . 0 0 0}$ infectados no Estado de São Paulo, Brasil endurece combate ao coronavírus. El País, São Paulo. 2020.

Krammer F. SARS-CoV-2 vaccines in development. Nature. 2020; 586: 516-27. Available.from: http://www.nature.com/articles/s41586-020-2798-3

LANA RM; COELHO FC; GOMES MFC; CRUZ OG; BASTOS LS; VILLELA DAM; CODEÇO CT. Emergência do novo coronavírus (SARS-CoV-2) e o papel de uma vigilância nacional em saúde oportuna e efetiva. CSP -Caderno de Saúde Pública. v.36, n.3, p.1-5. Fap UNIFESP. 2020.

MENDONÇA H. Governo anuncia 40 bilhões em crédito para financiar salários de pequenas e médias empresas por 2 meses. El País, São Paulo. 2020.

MENEZES ME. Diagnóstico laboratorial do coronavírus (SARS-CoV-2) causador da COVID-19. Sociedade Brasileira de Análises Clínicas. Rio de Janeiro: Sbac. 2020.

Ministério da Saúde. Segunda dose da vacina covid-19 deve ser tomada mesmo fora do prazo. Disponível em: https://www.gov.br/saude/pt/br/assuntos/noticias/segundadose-da-vacina-covid-19deve-ser-tomada-mesmo-fora-do-prazo. Acessado em: 28/06/2021.

Mukherjee R. Global efforts on vaccines for COVID-19: Since, sooner or later, we all will catch the coronavirus. Journal Bioscience. 2020; 45 (1): 68.

PAULES C, HYLARY DM, ANTHONY F. Coronavirus Infections-More Than Just the Common Cold. Jama. 2020. v.323, n.8, p. 707-708. 2020.PFEIFFER D. Pangolim, mamífero em extinção, pode ser possível hospedeiro intermediário do coronavírus, dizem cientistas chineses. G1. Universidade Agrícola do Sul da China. 2020.

PEREIRA, V. A. Existências ameaçadas: A Educação Ambiental em tempos de COVID 19. Brazilian Journal of Development. Curitiba, v. 6, n.4, p21254-21271apr. 2020.

PIRES M. As políticas que estão sendo adotadas para o combate ao Covid19: Experiência internacional e o Brasil. Instituto Brasileiro de Economia -IBRE. 2020.ROBBINS J. A Ecologia da Doença. The New York Times, 2012.

PNI. MINISTÉRIO DA SAÚDE Disponível em https://www.gov.br/saude/ptbr/media/pdf/2021/janeiro/29/PlanoVacinaoCovid_ed4_15fev21_cgpni_18h05.pdf, acesso 25 de fevereiro de 2021.

ROEHE P. Coronavírus, covid-19, SARSCoV-2 e outros -um ponto de vista virológico. 2020. Jornal da Universidade UFRGS. 2020. 
.ORGANIZAÇÃO DAS NAÇÕES UNIDAS. UNEP Frontiers 2016 Report: Emerging Issues of Environmental Concern. S.1, 2016. Brazilian Journal of Development, Curitiba, v.6, n.11,p.89390-89400, nov.2020.ISSN 2525-876189400

SINGHAL T. A Review of Coronavirus Disease-2019 (COVID-19). The Indian Journal of Pediatrics. v. 87, p 281-286. 2020.

SOUZA C. Políticas Públicas: uma revisão da literatura. Sociologias. n. 16, p. 2045, 2006.

U.S. Department of Health and Human Services, Food and DrugAdministration, Center for Biologics Evaluation and Research. Development and Licensure of Vaccines to Prevent COVID-19 [Internet]. 2020 [cited 2020 Sep 5]. Available: from: https://www.fda.gov/regulatoryinforma-tion/search-fda-guidance documents/ development-and-licensure-vaccinesprevent -covid-19

WESTCOTT B; DENG, S. China proíbe consumo de animais silvestres após surto do novo coronavírus. CNN International. [S.I]. 2020.

World Health Organization. Coronavirus disease (COVID-19) pandemic. Disponível em: https://www.who.int/emergencies/diseases/novel-coronavirus-2020.

Wu Di. et al. The SARS-CoV-2 outbreak: what we know. Rev: International Journal of Infecti ous Diseases. Universidade Federal do Paraná -Campus Toledo. v. 94, n. 1, p. 44-48.

ZANELLA JRC. Zoonoses emergentes e reemergentes e sua importância para saúde e produção animal. Pesquisa Agropecuária Brasileira-PAB. Brasília/DF. v.51, n.5, p.510-519.

ZHOU P, et al. A pneumonia outbreak associated with a new coronavirus of probable bat origin. Nature, v. 579, n. 7798, p. 270-273, 3 fev. 2020. Springer Science and Business Media LLC. 